\title{
Perancangan Website Badan Narkotika Nasional Provinsi Jawa Tengah
}

\author{
Central Narcotics Agency Of Central Java Narcotics Board Design \\ Zhientian Aldianto Pratama ${ }^{\mathbf{1},}$ Suharnawi ${ }^{2}$
${ }^{1,2}$ Program Studi Sistem Informasi - S1, Fakultas Ilmu Komputer - Universitas Dian
Nuswantoro \\ Jl. Imam Bonjol No. 207 Semarang 50131 Telp. (024) 3517261 \\ e-mail: ${ }^{1}$ zhientianrainbow@ gmail.com, ${ }^{2}$ nawigr@gmail.com
}

\begin{abstract}
Abstrak
Badan Narkotika Nasional Provinsi Jawa Tengah merupakan lembaga non kementrian yang berfokus pada pencegahan, pemberantasan, penyalahgunaan dan peredaran gelap psikotropika atau bahan adiktif lainnya. Dalam menjalankan proses bisnis tersebut, Badan Narkotika Nasional Provinsi Jawa Tengah memerlukan sistem untuk menjadi media publikasi informasi dan pengaduan masyarakat yang digunakan untuk meningkatkan informasi publik dan meningkatkan hubungan dengan masyarakat mengingat lembaga ini secara tidak langsung bekerja untuk keperluan masyarakat. Obyek penelitian adalah Badan Narkotika Nasional Provinsi Jawa Tengah. Metode pengembangan sistem yang digunakan adalah Rapid Application Development. Tujuan penelitian membuat website yang digunakan sebagai media untuk memberikan informasi dan media untuk pelayanan masyarakat dalam hal pengaduannya atau aspirasinya. Sistem yang dibuat akan memudahkan dalam pengelolaan konten berita atau informasi dan pengaduan. Penyajian informasi memperhatikan susunan menu akses yang terstruktur sehingga mudah untuk dioperasikan, dipahami dengan jelas dengan menciptakan sistem back-end untuk keperluan Bagian Sarpras (Admin) dalam mengelola konten.
\end{abstract}

Kata kunci : Badan Narkotika Nasional Provinsi Jawa Tengah, Perancangan Website, Codeigniter, MVC, Front-end, Back-end, Framework, RAD

\begin{abstract}
The Central Java National Narcotics Agency is a non-ministerial institution that focuses on prevention, eradication, abuse and illicit circulation of psychotropic substances or other addictive ingredients. In carrying out the business process, the Central Java National Narcotics Agency requires a system to become a media for public information and complaints that is used to improve public information and improve relations with the community, as this institution indirectly works for the community's needs. The object of research is the Central Java National Narcotics Agency. The system development method used is Rapid Application Development. The purpose of the research is to create a website that is used as a medium to provide information and media for community service in terms of complaints or aspirations. The system created will facilitate the management of news content or information and complaints. Presentation of information takes into account the arrangement of structured access menus so that it is easy to operate, clearly understood by creating a back-end system for the Sarpras (Admin) section in managing content.
\end{abstract}

Keywords : National Narcotics Board of Central Java Province, Website Construction, Codeigniter, MVC, Front-end, Back-end, Framework, RAD 


\section{PENDAHULUAN}

Badan Narkotika Nasional adalah Lembaga Pemerintah Non Kementerian Indonesia yang memiliki tugas dan tanggung jawab dalam melaksanakan tugas pemerintahan dibidang pencegahan, pemberantasan, penyalahgunaan dan peredaran gelap psikotropika, prekursor, dan bahan adiktif lainnya kecuali bahan adiktif untuk alkohol dan tembakau [1].

Dalam survei yang dilakukan oleh BNNP Jateng tahun 2016 ada sekitar 57 kasus perhari penyalahgunaan narkotika yang menyebabkan kematian. Pada umumnya pengguna mempunyai dalih untuk mengurangi stres dan kelelahan. Ketidaktahuan bahaya dan kerugian penggunaan obat terlarang perlu disosialisasikan. Dengan demikian perlu dibuat suatu portal yang menampilkan informasi yang dapat memberikan pengetahuan tentang narkotika, serta tidak adanya sarana atau media dalam mengungkapkan suara atau opini masyarakat ke BNNP Jateng itu sendiri, baik itu tentang layanan, pemberdayaan masyarakat, rehabilitasi, atau pemberantasan. Komunikasi sangatlah penting dalam membangun sinergi dalam mencapai tujuan bersama, karena pada BNNP Jateng sendiri lembaga yang tujuannya berorientasi kepada masyarakat, maka suara masyarakat juga sangat dibutuhkan dalam pembentukan kinerja dalam mencapai tujuan.

Berdasarkan latar belakang masalah di atas maka penelitian tentang Perancangan Website Badan Narkotika Nasional perlu dibuat dengan tujuan memberikan solusi yaitu informasi publik yang jelas mengenai narkotika dan sebagai prasarana untuk menghubungkan lembaga dengan masyarakat. Diharapkan dapat memberikan kontribusi positif untuk memberikan pengetahuan tentang informasi terbaru mengenai narkotika dan meminimalisir penyalahgunaan obat terlarang.

\section{METODE PENELITIAN}

Metode Pengembangan sistem yang digunakan dalam penelitian ini adalah metode $R A D$ (Rapid Application Development), metode RAD ini terdiri oleh berbagai tahap yaitu Fase Perencanaan Syarat-Syarat, Fase Perancangan, Fase Konstruksi, Fase Pelaksanaan.

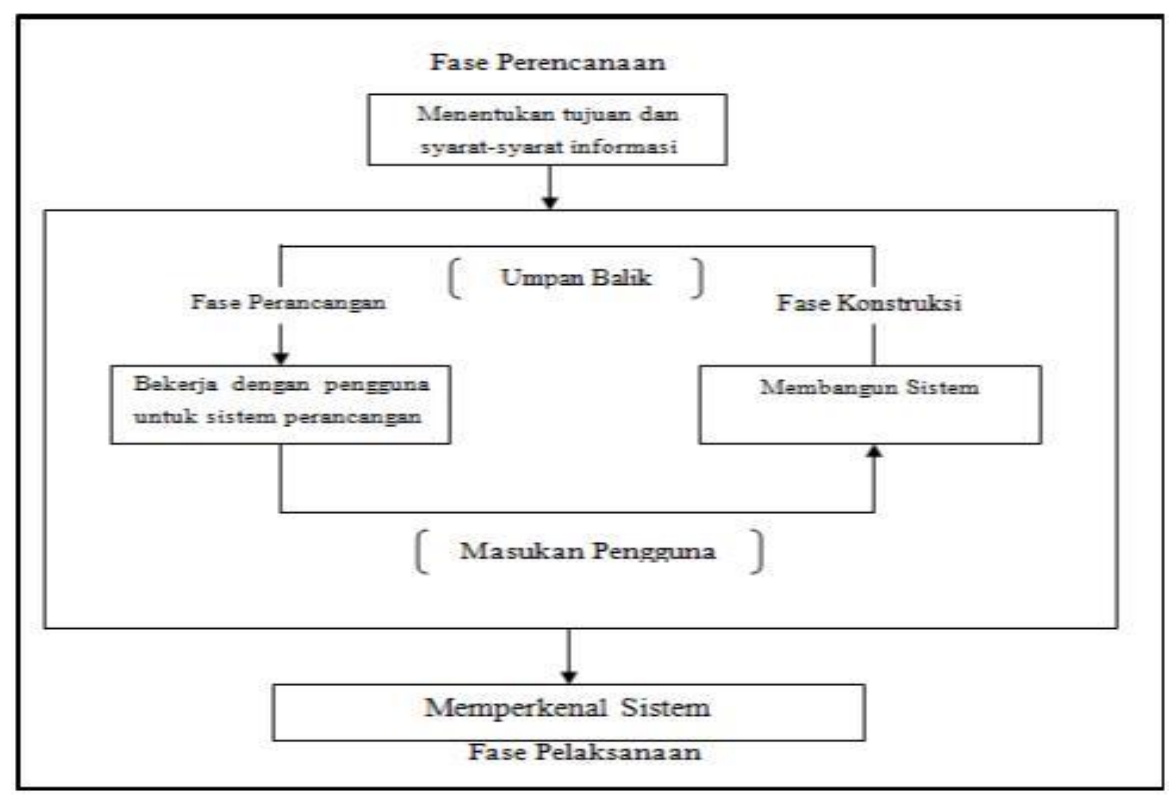

Gambar 1. Kerangka Metode RAD ( Rapid Application Development)

RAD adalah metode pengembangan sistem yang memfokuskan perancangan melalui pendekatan berorientasi objek yang mencakup suatu metode pengembangan serta perangkat lunak. Pada Metode RAD ini bertujuan untuk memperpendek waktu dalam perancangan yang 
biasanya cukup lama diperlukan dalam siklus hidup pengembangan sistem tradisional antara perancangan dan penerapan suatu sistem informasi. Metode RAD ini menghasilkan persyaratan untuk memenuhi syarat-syarat bisnis yang berubah secara cepat. Adapun keempat fase yang mencakup langkah dalam metode RAD tersebut adalah Requirements Planning (perencanaan syarat-syarat), Design (Perancangan), Construction (Pembangunan) dan Implementation (Implementasi atau memperkenalkan sistem). Adapun Fase pengembangan aplikasi menggunakan metode RAD [2]:

1. Fase Perencanaan Syarat Syarat (Requirements Planning)

Fase ini Pengguna dan Pembuat sistem berkolaborasi dalam mengidentifikasi dan memutuskan fungsi atau prosedur apa saja yang harus ada dalam aplikasi tersebut.

2. Fase Perancangan (Design)

Fase ini Pembuat sistem membangun sebuah desain sistem atau rancangan dari sistem dan diberikan masukan oleh pengguna tentang aspek-aspek yang desain nonteknis dari pengguna yang mengerti bagaimana sistem itu akan digunakan untuk membantu kinerja pengguna.

3. Fase Konstruksi (Construction)

Fase ini ialah mengimplementasikan setiap desain yang dirancangkan dan dilakukan pengkodean sistem sehingga membantuk sistem yang diharapkan dapat membantu kinerja sistem yang dihasilkan oleh metode pengembangan.

4. Fase Pelaksanaan (Implementation)

Fase ini sistem telah selesai diciptakan dan sistem siap untuk diperkenalkan untuk pengguna, maka pada fase terakhir ini sistem akan di ujicoba atau testing untuk kelayakan sistem mengerjakan tugas dari tujuannya dibuat sistem tersebut.

\section{HASIL DAN PEMBAHASAN}

\subsection{Fase Perencanaan Syarat-syarat}

A. Analisa Kebutuhan Masalah

1. Analisa Sistem Yang Sedang Berjalan

Sistem yang berjalan pada proses bisnis publikasi informasi dan pengaduan masyarakat pada Badan Narkotika Nasional Provinsi Jawa Tengah, Sebagai berikut :

a. Informasi mengenai berita dan informasi narkotika terbaru disebarkan melalui sosial media dari BNNP-Jateng dan sebagian dipublikasikan melalui koran lokal dan media massa lainnya kepada masyarakat umum.

b. Pengaduan Masyarakat yang dilakukan oleh masyarakat yang ingin mengadukan tentang narkotika atau pelayanan dilalukan dengan cara datang langsung ke kantor BNNP Jawa Tengah atau telfon ke bagian administrasi umum pada BNNP Jawa Tengah.

2. Kelemahan Sistem Yang Sedang Berjalan

Berdasarkan analisa sistem yang berjalan pada BNNP Jawa Tengah, maka didapat kelemahan sistem yang sedang berjalan, sebagai berikut :

a. Publikasi informasi dan berita tidak efektif karena terbatasnya penyampaian pada sosial media dan dapat diragukan jika akun pada sosial media tersebut tidak terverifikasi.

b. Masyarakat harus datang sendiri untuk memberikan pengaduannya atau permohonannya sehingga masyarakat kesulitan dalam mengakses fasilitas permohonan tersebut karena terpautnya jarak tempuh antara masyarakat dengan kantor BNNP Jawa Tengah.

3. Solusi Pemecahan Masalah

Pemecahan masalah dari identifikasi masalah yang telah dirumuskan dalam penelitian ini adalah dengan perancangan website sebagai media publikasi dan pengaduan masyrakat pada Badan Narkotika Nasional Provinsi Jawa Tengah. 
Website yang akan dibuat akan digunakan untuk media untuk mempublikasikan informasi dan berita yang berasal langsung dari BNNP Jawa Tengah sekaligus memfasilitasi masyarakat untuk mengadukan keluhannya atau aspirasinya mengenai pelanggaran maupun pelayanan BNNP Jawa Tengah.

\section{B. Analisa Kebutuhan Sistem}

Dalam mewujudkan dan menjalankan perangkat lunak yang dibangun ada beberapa hal yang harus dipenuhi sistem agar berjalan dengan baik dan sesuai tujuannya dibuatnya sebuah sistem. Oleh karena itu Badan Narkotika Nasional Provinsi Jawa Tengah membutuhkan beberapa kebutuhan untuk sistem yang akan dibuat :

Berikut analisa kebutuhan-kebutuhan sistem yang harus dipenuhi untuk menjalan sistem yang dibangun :

1. Kebutuhan Perangkat Lunak (Software)

Agar Komputer bisa berfungsi dengan baik dalam membangun dan menjalankan sistem, perlu didukung oleh perangkat lunak yang memadai sebagai berikut:

a. Sistem Operasi, dalam menjalankan perangkat lunak yang dibangun minimal Windows 7 Professional.

b. WAMP, sebagai server local digunakan dalam pembuatan perangkat lunak yang menyediakan paket software Apache, dan MySQL.

c. Google Chrome, Sebagai browser yang digunakan untuk mengakses perangkat lunak yang dibangun.

d. Sublime Text, Sebagai teks editor yang digunakan untuk menulis standarisasi coding dan script dalam membagun perangkat lunak berbasis website.

e. Internet, Sebagai konektifitas untuk mengakses file perangkat lunak berbasis website yang telah dihosting.

2. Kebutuhan Perangkat Keras (Hardware)

Spesifikasi perangkat keras yang baik dalam mendukung membangun dan menjalankan sistem [3], sebagai berikut :
a. CPU Intel Core 2 Duo atau AMD A9 7th Generations.
b. Ram Minimal 2 GB.
c. Harddisk Minimal 320 GB.
d. VGA $128 \mathrm{MB}$.
e. Monitor dengan resolusi 1366 x 768 LED.

\subsection{Fase Perancangan}

A. Perancangan Proses

1. Diagram Use Case

Diagram Use Case ini mengilustrasikan secara grafis mengenai interaksi kasus penggunaan atau fungsi terhadap sistem terhadap penggunanya (Actor). Actor dalam use case adalah entitas yang menggunakan sistem, dapat didefiniskan sebagai subjek manusia, waktu, atau benda [4]. 


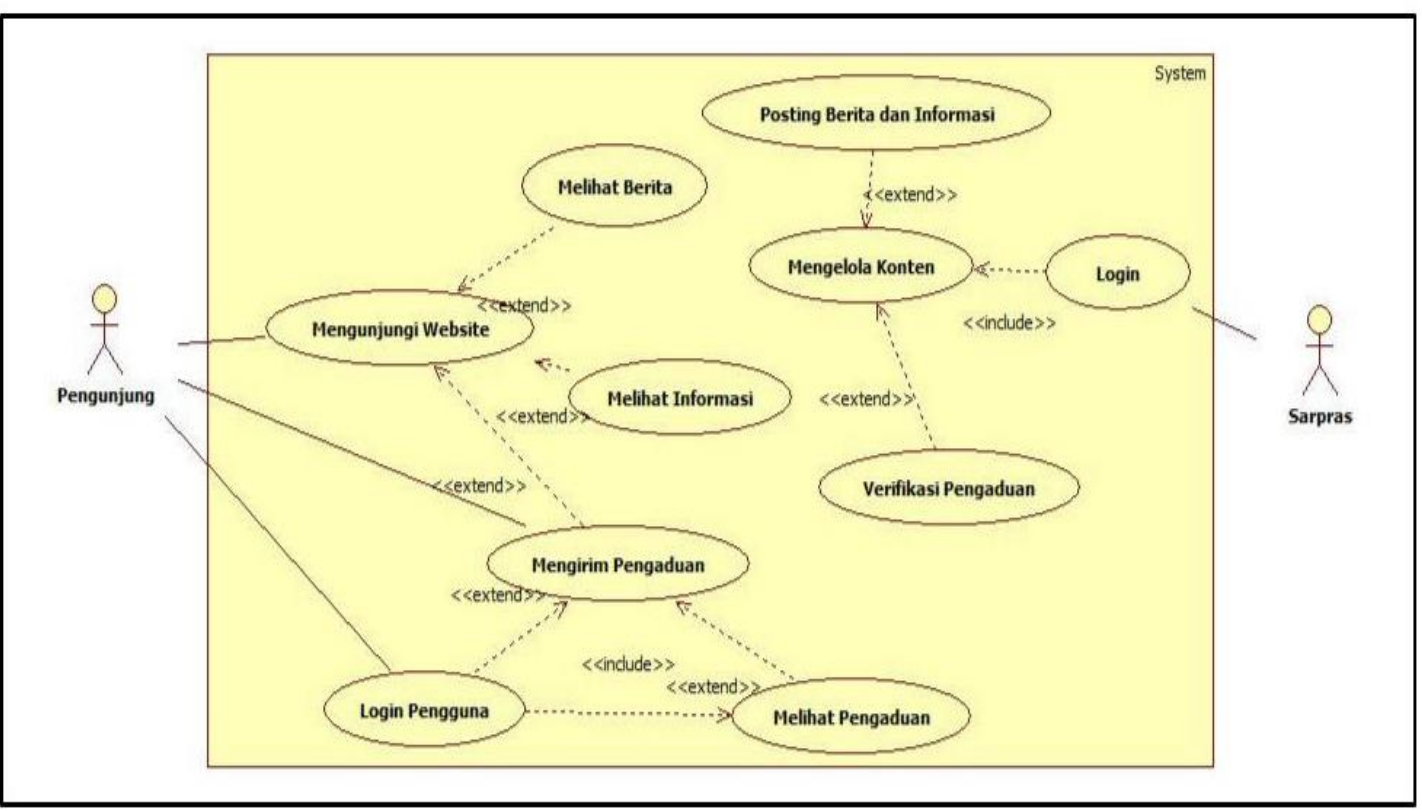

Gambar 2. Diagram Use Case

2. Diagram Activity Posting Berita dan Informasi

Didalam Diagram Activity Posting Berita dan Informasi terdapat dua entitas aktif yaitu pengunjung dan Admin sehingga arus relasi bersifat dua arah.

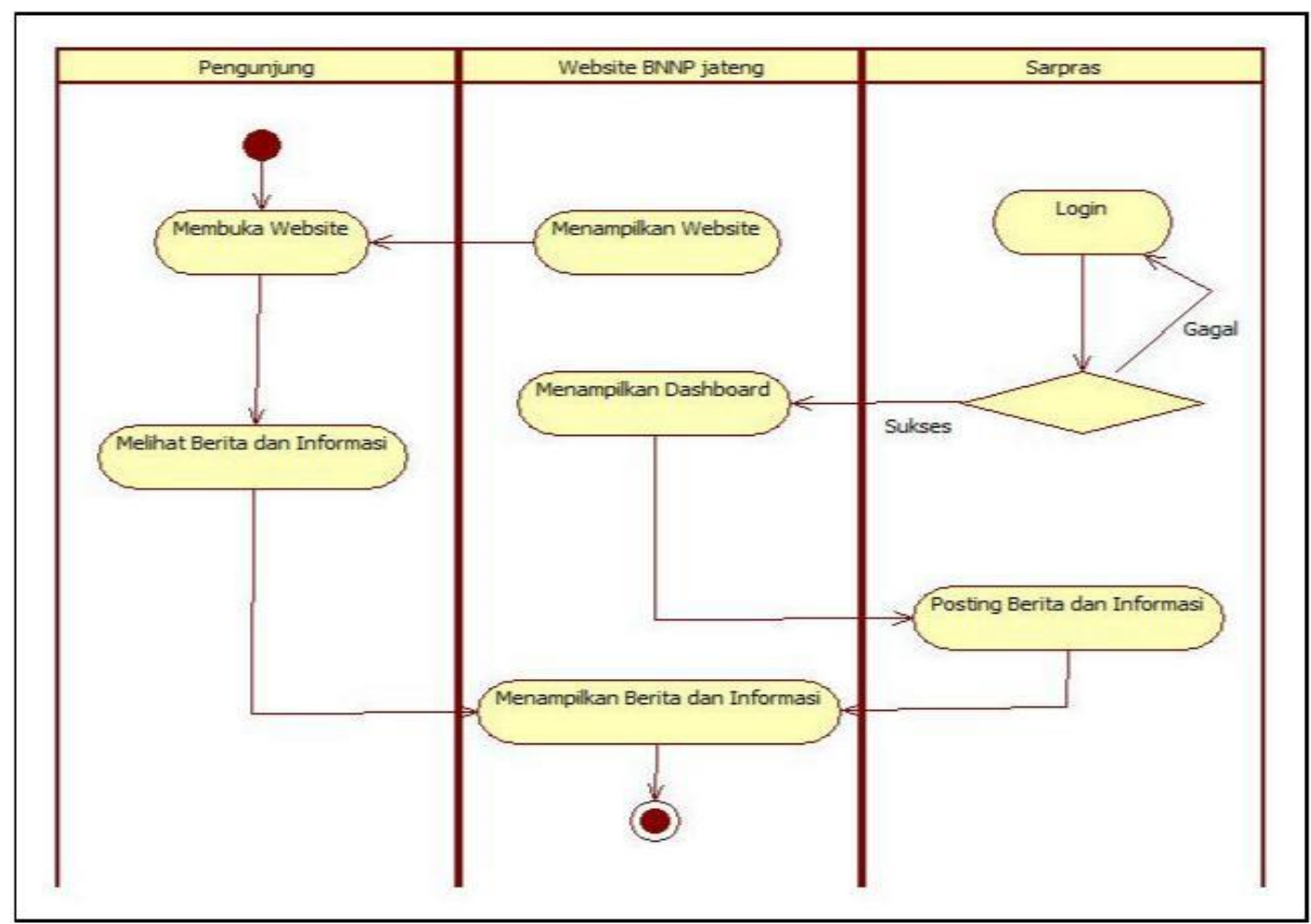

Gambar 3. Diagram Activity Posting Berita dan Informasi 
3. Diagram Activity Pengaduan Masyarakat

Didalam diagram activity pengaduan masyarakat dimulai oleh pengunjung yang ingin mengadu berupa kritikan tentang pelayanan atau melaporkan tindak kriminal narkotika.

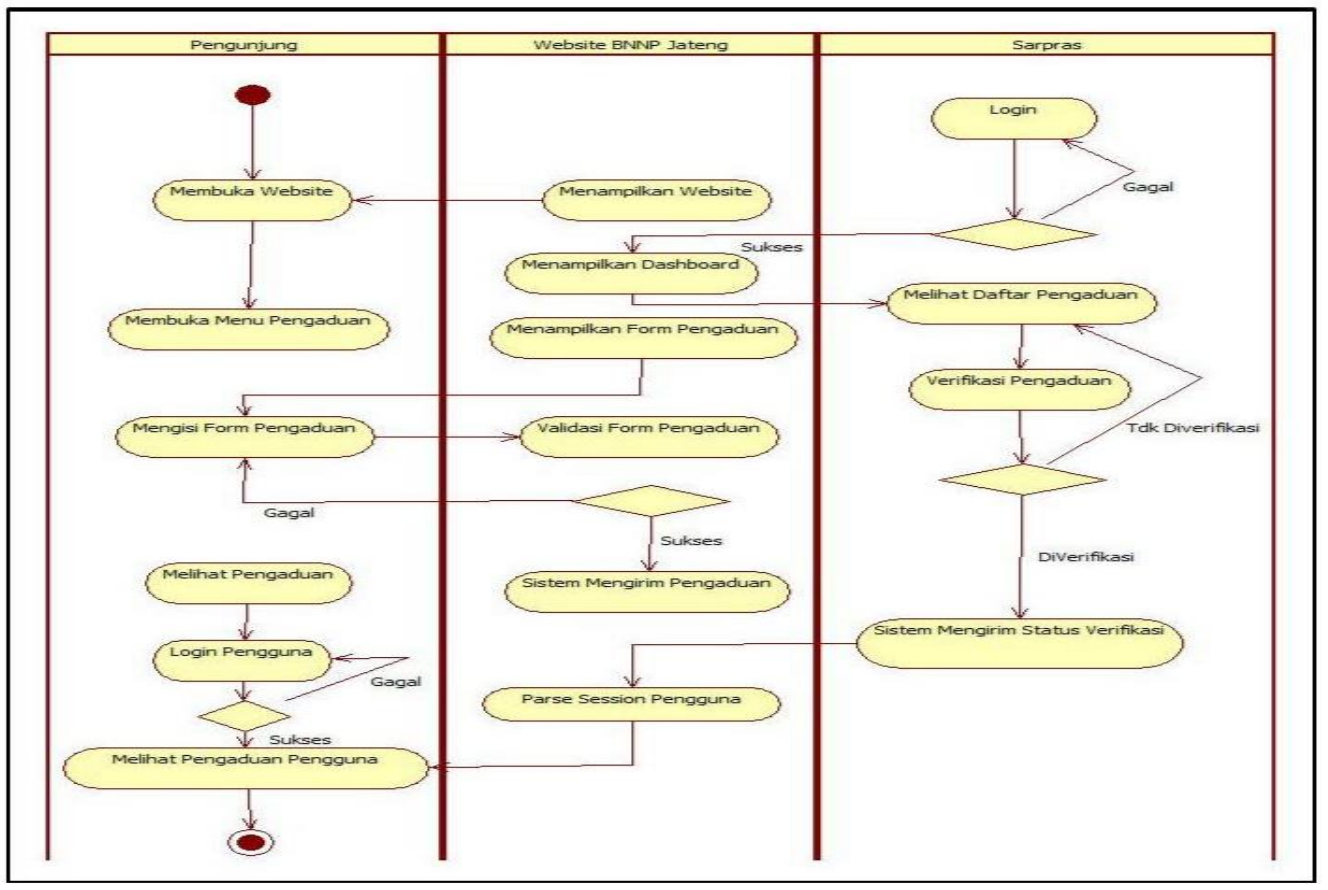

Gambar 4. Diagram Activity Pengaduan Masyarakat

4. Sequence Diagram Posting Berita dan Informasi

Diagram Sequence Posting Berita dan Informasi Mengilustrasikan bagaimana objek antara halaman utama, dan proses route logika, serta pemanggilan fungsi models sampai ke database.

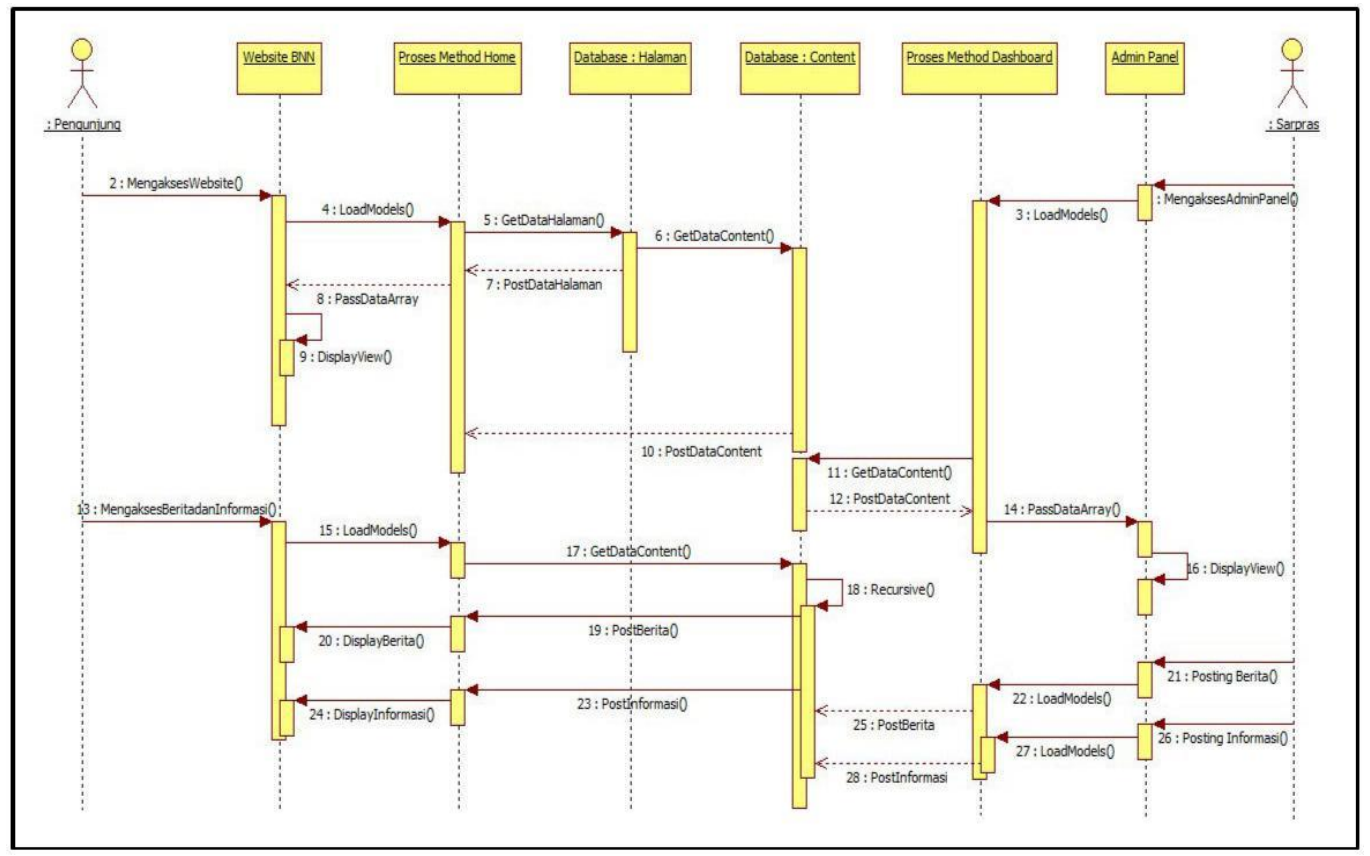

Gambar 5. Diagram Sequence Posting Berita dan Informasi 
5. Sequence Diagram Pengaduan Masyarakat

Diagram Sequence Pengaduan Masyarakat mengilustrasikan interaksi antar objek pada proses pengaduan masyarakat yang meliputi aktor Pengunjung dan Admin serta Table Pengaduan sebagai koleksi data.

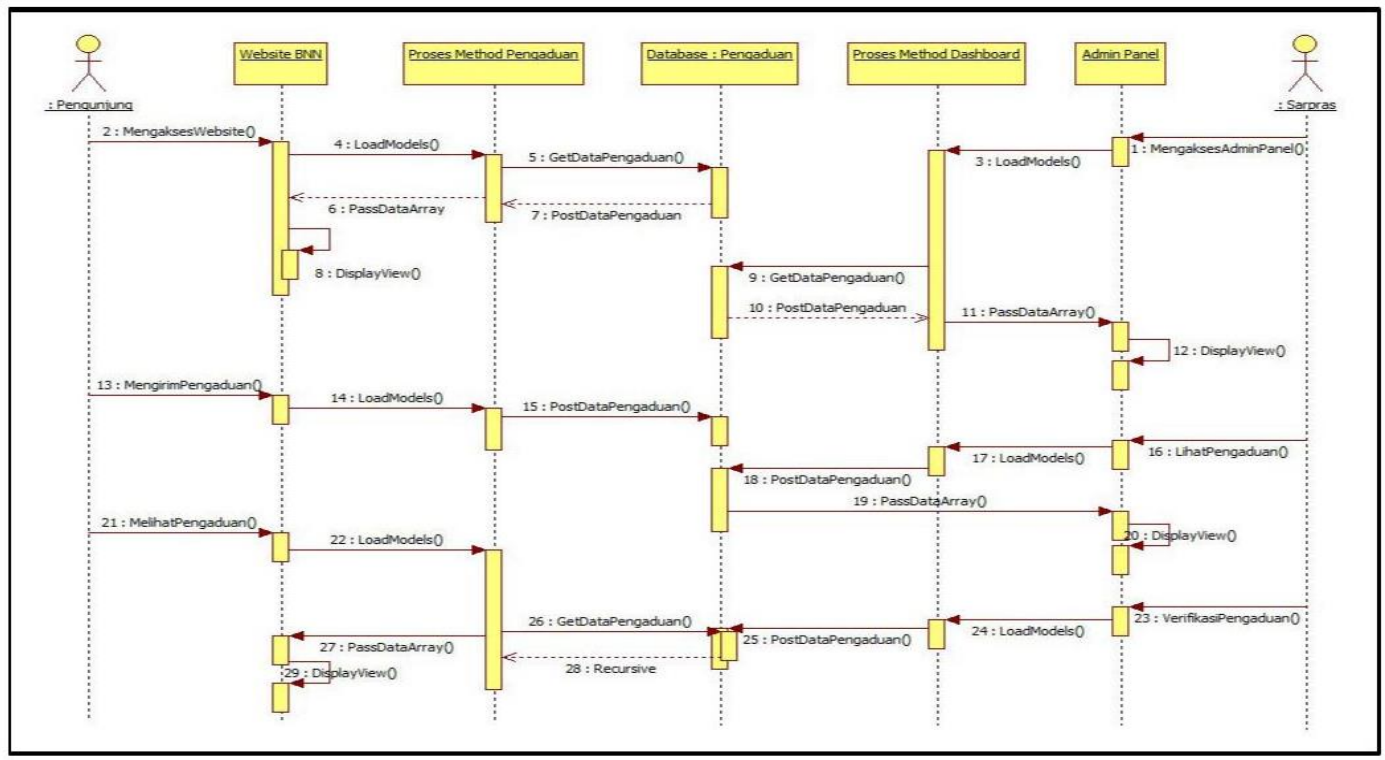

Gambar 6. Diagram Sequence Pengaduan Masyarakat

B. Perancangan Basis Data

Perancangan Basis Data adalah perancangan yang bertujuan untuk membentuk struktur database dan relasi antar tabel.

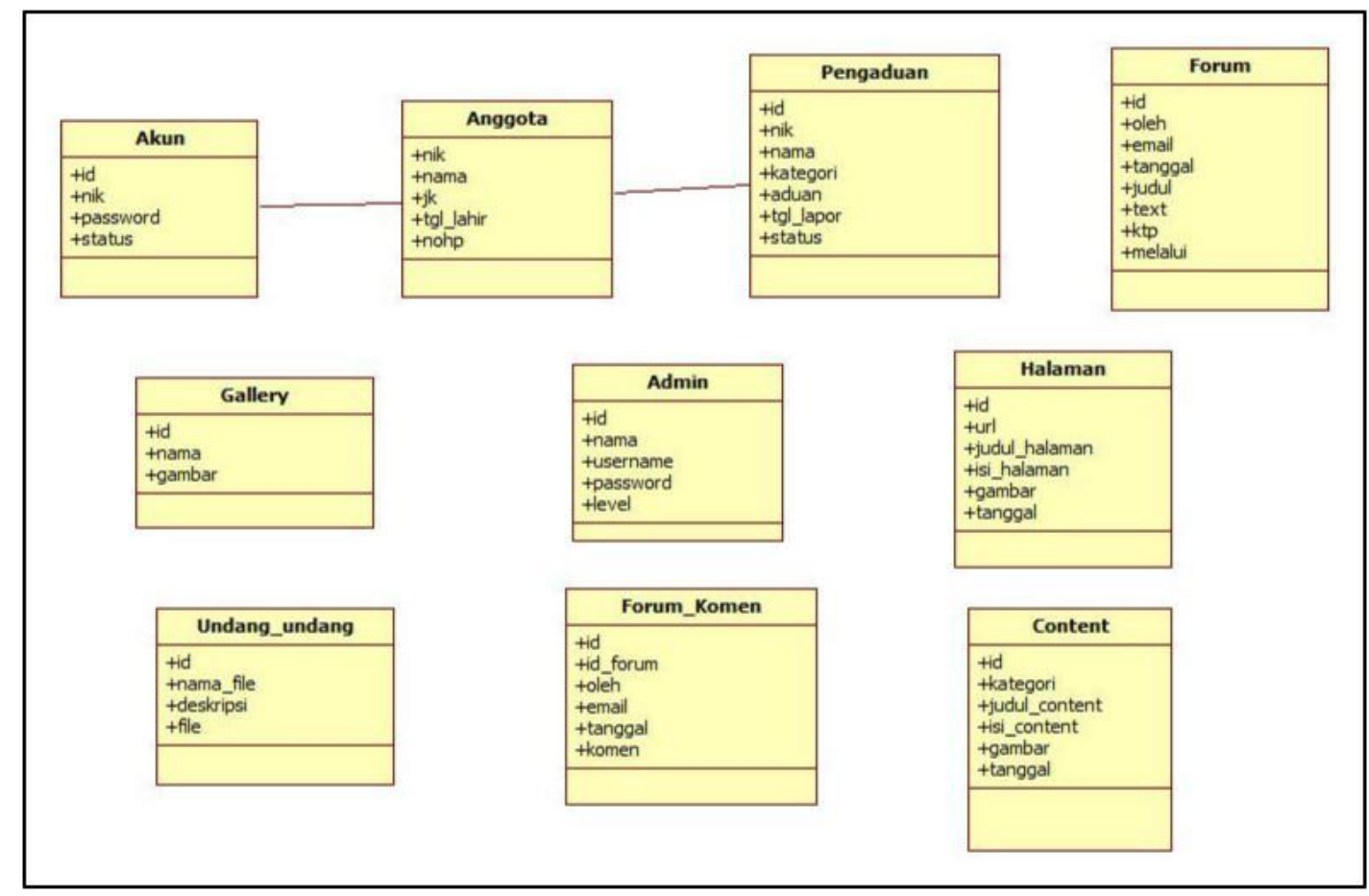

Gambar 7. Rancangan Tabel 


\subsection{Fase Konstruksi}

Setelah fase perancangan telah selesai, maka tahap berikutnya adalah fase konstruksi, fase ini adalah fase dimana fase yang mengimplementasikan hasil dari fase perancangan dalam bentuk coding yang akan membentuk sebuah program aplikasi berbasis website yang dapat sesuai agar sistem yang dihasilkan akurat kepada kebutuhan pengguna. Dalam Fase Konstruksi ini penulis menggunakan WAMPSERVER dalam menanamkan server lokal pada komputer untuk memuat bahasa script PHP sebagai kategori bahasa client-server. Sublime Text sebagai text editor digunaka penulis dalam menuliskan kode program. Dan Dalam Fase Konstruksi ada dua bahasan pokok penelitian yang sudah dirumuskan yang harus ada dalam program aplikasi berbasis website yaitu Proses Posting Berita dan Informasi dan Proses Pengaduan Masyarakat. Selain itu juga sarana pendukung yang diperlukan agar sistem dapat berjalan sesuai harapan.

\subsection{Fase Pelaksanaan}

Pada tahap fase pelaksanaan, menampilkan hasil dari fase perancangan yang telah dilakukan, proses selanjutnya melakukan sebuah implementasi sistem yang diinginkan.

1. Halaman Utama Website

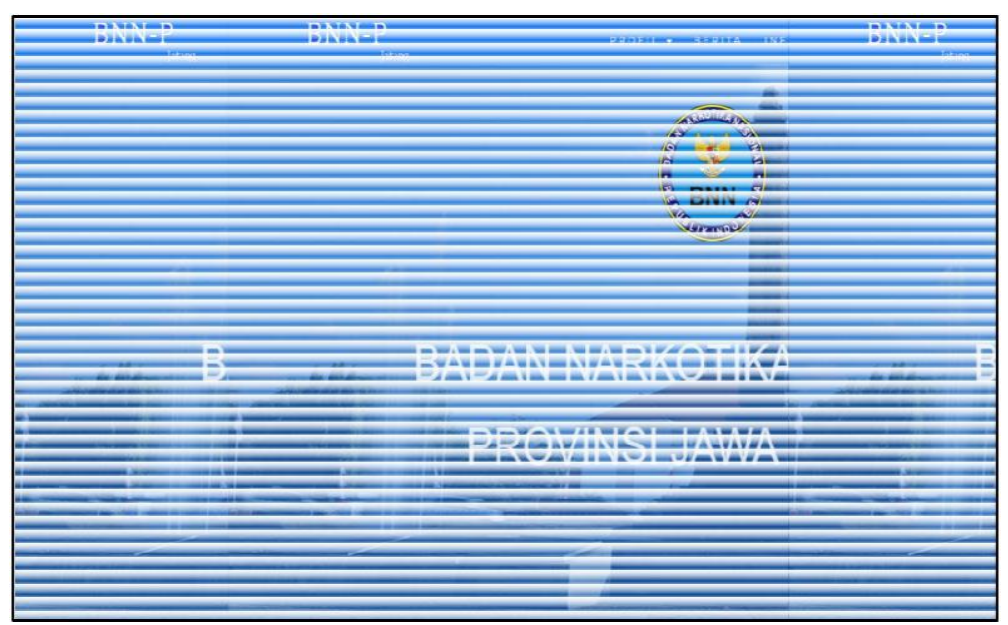

Gambar 8. Halaman Utama Website

2. Form Pengaduan Masyarakat

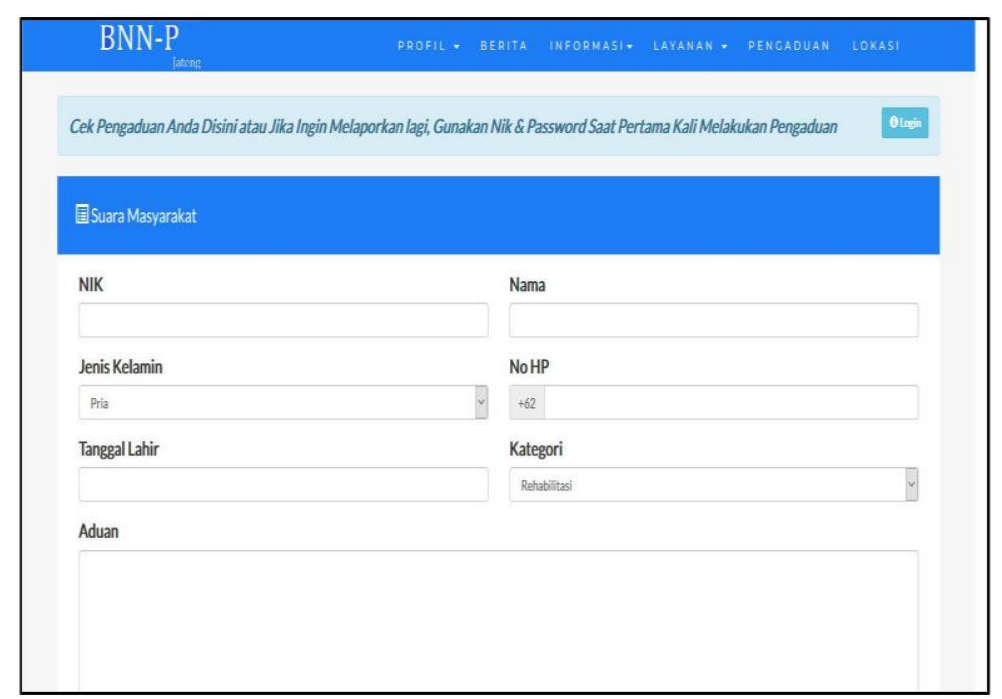

Gambar 9. Halaman Form Pengaduan Masyarakat 
3. Halaman Utama Admin Panel

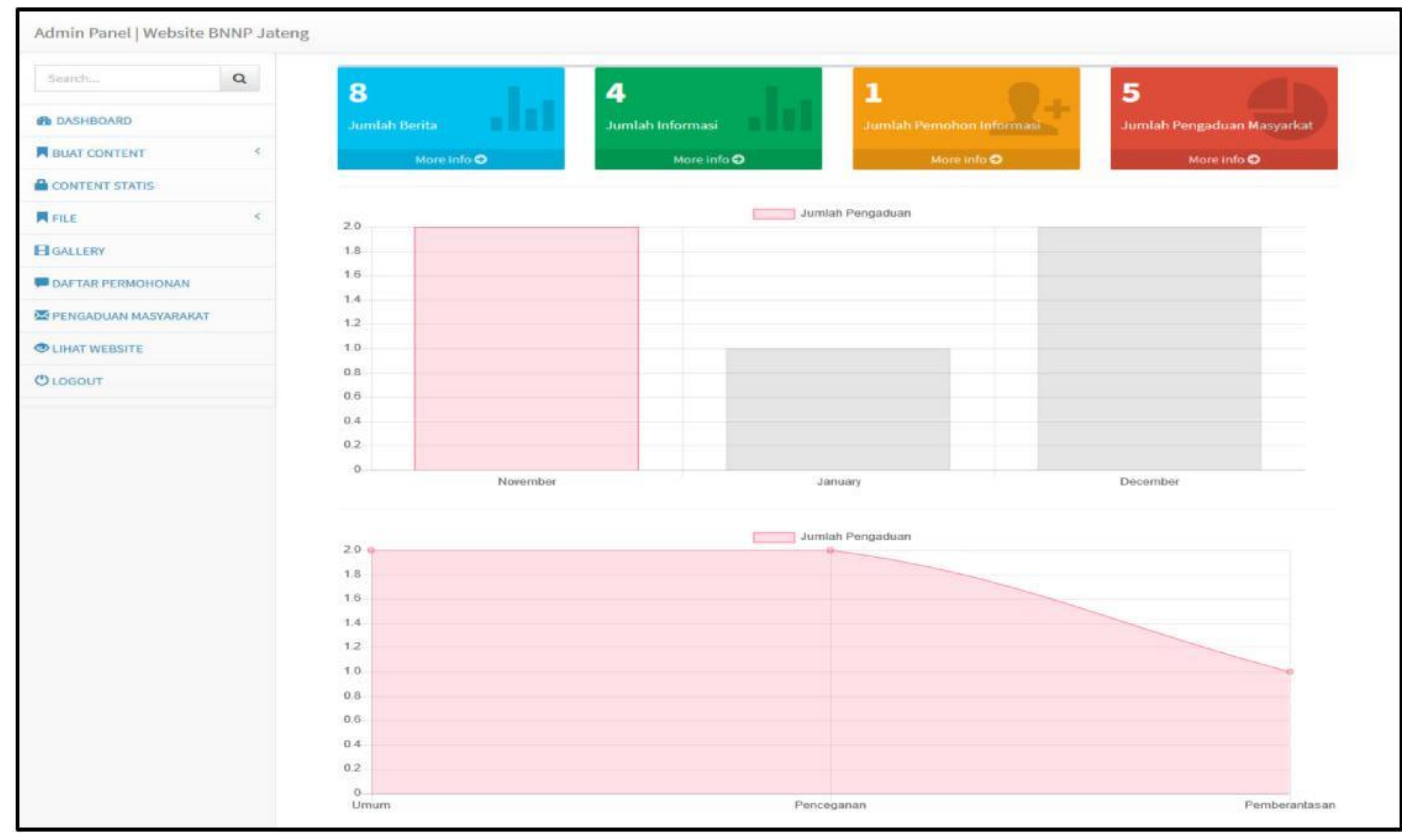

Gambar 10. Halaman Utama Admin Panel

4. Halaman Daftar Pengaduan

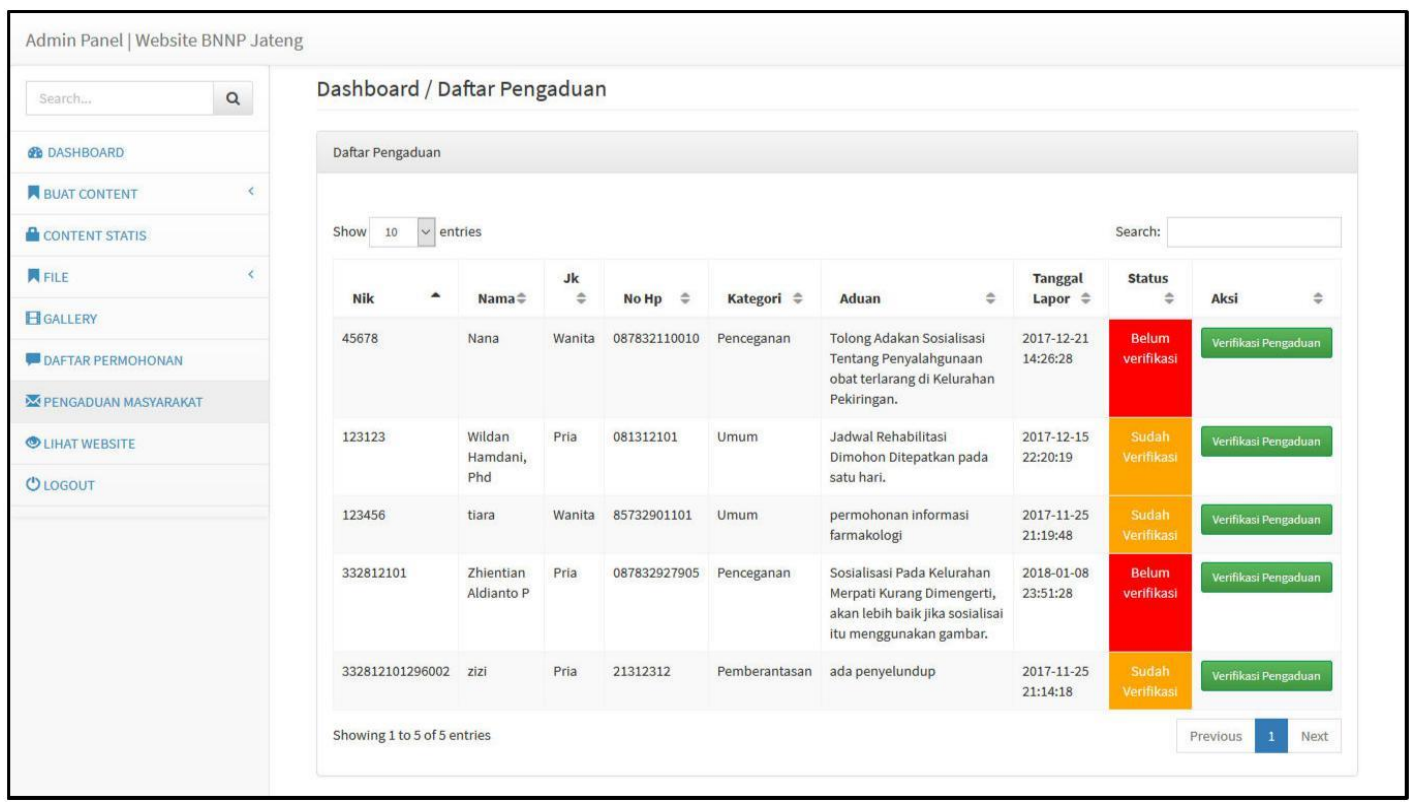

Gambar 11 Halaman Daftar Pengaduan

Sistem informasi Badan Narkotika Nasional Provinsi Jawa Tengah dapat dijadikan prioritas layanan kepada masyarakat untuk mendapatkan dan menyampikan informasi [5].

Sistem informasi pada umumnya dioperasikan sesuai dengan tujuan sistem tersebut dibuat. Bagian-bagain yang mengoperasikan sistem tentunya sesuai dengan tugas dan tanggung jawab sesuai dengan struktur organisasi. Dengan demikian penyediaan informasi dan layanan sesuai dengan tujuan sistem dibuat dapat terwujud dengan baik. 


\section{KESIMPULAN}

Dari Hasil Penelitian Tentang Perancangan Website Pada Badan Narkotika Nasional Provinsi Jawa Tengah dapat disimpulan beberapa hal, sebagai berikut :

1. Website ini dapat berguna dan membantu kinerja lembaga dalam menghubungkan informasi yang dimiliki pihak BNNP Jawa Tengah dengan masyarakat dan meminimalisir berita hoax oleh media yang tidak bertanggung jawab.

2. Memberikan kemudahan dalam pengelolaaan berita dan informasi kepada pegawai Badan Narkotika Nasional Provinsi Jawa Tengah.

Website ini diharapkan membantu masyarakat dalam menyampaikan pengaduan dan sarannya kepada pihak BNNP Jawa Tengah sebagai fasilitas yang baru selain media telpon dan membantu pegawai dalam mengelola pengaduan masyarakat.

\section{DAFTAR PUSTAKA}

[1] Wikipedia.org. (2017, Maret) Badan Narkotika Nasional. [Online]. https://id.wikipedia.org/wiki/Badan_Narkotika_Nasional

[2] S Pressman Roger, Software Engineering: A Practitioner's Approach, 6th ed. New York, United States of America: McGraw-Hill, Inc, 1982.

[3] Wildan and Suharnawi, Pengembangan Sistem Informasi Pariwisata Kabupaten Tegal Berbasis Website. Semarang, Indonesia: JOINS, 2018.

[4] A Suhendar and H Gunadi, Visual Modelling Menggunakan UML dan Relational Rose. Bandung, Indonesia: Informatika, 2002.

[5] Sya'bandiyah, Saputra, and Pramono, Rekomendasi Penentuan Prioritas Sistem Informasi di BNN Kota Malang Menggunakan Metode EasyWinWin. Malang, Indonesia, 2018. 